\title{
“Internet plus” Driven by the Municipal Government, the Public, and Benign Operation Mechanism of WeChat
}

\author{
Xiaofeng Liang, Lijuan Chen \\ Institute of Media, Xi'an Peihua University, Xi'an, China, 710125
}

Keywords: “Internet plus”; municipal government; public; WeChat; operation mechanism

\begin{abstract}
In order to enhance the "Internet plus" driving under the influence of municipal government and WeChat public platform, this paper establishes a unified and standardized "Internet plus" with multilevel linkage, through the statistics of "Internet plus" driven by the Shaanxi municipal government, the WeChat public operations and backstage management, with application analysis, qualitative analysis and quantitative thinking methods and empirical research, to explore the mechanism of "Internet plus" system driven by the municipal government of Shaanxi province, the public and WeChat benign operation.
\end{abstract}

\section{Social Background}

In January 12, 2017, the State Council issued the "Internet plus government services" technology system construction guide ", requiring all localities and departments to actively promote the online government service platform for the construction of local government services, to carry out relevant institutional innovation and application service innovation.

At present, the territory of Shaanxi, Xianyang, Tongchuan, Baoji, Hanzhoung, Weinan, Shangluo, Yanan and Yulin. A total of 9 cities, as of April 30, 2017, in addition to Baoji, the other 8 cities have opened government account for the main WeChat Internet Information Office, the Municipal People's government or municipal Party committee propaganda department.

"Internet plus" driven by the municipal government of Shaanxi province can open all the chief WeChat, whether through the benign operation, in the people's livelihood, medical, education and other fields to provide users with government information release, information query, service and other comprehensive government services, build "Internet + government service platform, improve government services intelligence the level, will have more and more important practical significance.

\section{Research Background and Significance}

As an important platform for the government to build the public information service system, the research of WeChat has become one of the hotspots in recent research. The research achievements of WeChat are interdisciplinary and distinctive. The existing research results for the scattered research on issues related to the WeChat scholar as the core of the system, the study on the municipal government WeChat operation mechanism has not been seen, and no scholars from the "Internet plus" view of Shaanxi prefecture level city government operation mechanism of WeChat. Holding the purpose of theoretical research to serve the real society, this paper attempts to systematically analyze the current situation of WeChat operation in prefecture level city of Shaanxi, and explore the mechanism conducive to the benign operation of Shaanxi municipal government WeChat public number from the perspective of theory and practice.

\section{Research Discovery}

As of April 30, 2017, according to data released Southern Weekend laboratory China chief WeChat ranking 100 list, the government of Shaanxi WeChat public number only "Xi'an release" on the list, Shaanxi province 8 prefecture level municipal government public WeChat all fail in an 
examination.

As a new way of communication in Internet era, WeChat government by its interactive communication space, more intimate features are part of the municipal government attention, the municipal government to the good will and strong ability to operate the chief WeChat, achieved good results in government affairs, information push and public service etc. and gradually build up a "Internet plus" driven "function features, with convenient service for the leading" intelligence platform.

However, the operation status of WeChat public account of Shaanxi prefecture level municipal government is not optimistic. No matter it is government WeChat's account design, government affairs publicity, information push or public service, it is lagging behind most of the provinces in the country. The specific situations are as follows.

First, the account location is blurred

Part of the Shaanxi municipal government fuzzy account WeChat public number of positioning, operation platform should publish information on the type, the relationship between information and the user is lack of clear understanding, such as the "wisdom of Xianyang, most of the content is released all kinds of information related to national policy, the province of Xianyang, and the lack of direct contact, can not meet the Xianyang users get information through the municipal government, the public demand for WeChat.

Second, the "custom menu" design does not meet the user's access to information and business needs

Both Shaanxi municipal government and WeChat public number designed to "custom menu", but the information service and the service function is limited, most of the public service function, setting requires multiple operations to enter the query page, WeChat did not give full play to the government, the public "public service connector", set up the service platform. The function is weak, unable to integrate various resources, to provide one-stop service to the public, to achieve "Internet plus" government, medical, transportation etc. For example, "smart city" set up by "smart Xianyang" menu, only to provide "city card" management, service function is single, can not meet the needs of users.

The content of WeChat public address of Shanxi prefecture level municipal government is mostly from the perspective of government and leadership. The language style still has strong official document color, and there is no awareness of effective communication with users. In the "Weinan issue" as an example, the April 24, 201726 release of the title and content the release form is as follows, the content involves the government work carried out, the language style of serious and dull, released in the main text, even if there are pictures, pictures are mostly introduced panorama conferences or activities.

Fourth, the design of the interaction system of the government and the people and the poor implementation of their interactive behavior

Most of the WeChat public numbers of Shaanxi prefecture level governments have quietly built up or released official news releases on the media. There has not been a sense of popularizing the platform through many ways, and there is no corresponding supporting system, which is lack of effective promotion. At the same time, in the daily operation of the process, the Shaanxi municipal government and the public interaction with the audience, WeChat small number of interactive forms only keywords automatic reply, contest or vote, some WeChat public number will appear without any response back to the user after the release of information, seriously affect the user experience [1].

First, there is a lack of cross sectoral coordination management architecture

Shaanxi province municipal government WeChat public number mainly by the Propaganda Department, Internet Information Office, office of the people's Government of a single department management and operation, comprehensive coordination ability can also play the Publicity Department released and government office, unable to achieve cross sectoral coordination, rapid acquisition and verification and authoritative information for the first time pushed to the user.

Second, the operation team is lack of professional management 
Shaanxi municipal government and WeChat public number operators are familiar with the way the work of the government, but the lack of new media skills, do not understand the needs of the public to do the municipal government and public operations, WeChat can make the new media the government to achieve smooth communication with public awareness is not enough, at the same time and the lack of professional management and operational guidance, overall operations poor.

Third, the lack of a scientific and effective working mechanism

The municipal government of Shaanxi province WeChat public operations personnel and fresh blood to supplement the lack of effective protection system, can not achieve full-time work, the quantity and quality caused by the WeChat platform released content directly can not be guaranteed, time limit, reply to user demands consultation class demands the longest time limit, the longest time limit demands of complaints can not guarantee the mechanism, seriously affect the user experience.

\section{The "Internet plus" Driven by Municipal Government of Shaanxi Province, the Public and Benign Operation of WeChat}

The ancient Greek philosopher Yi Zhen Lu wall put forward "the state and the law is a product of contract based on a human welfare agreement, to avoid infringement between people", that the government is reflected in the value of safeguarding public interests, the original social contract thought contains the initial idea of serving the people for the government [2].

In 1990s, Robert Hart and Jeanne Hart on board co authored "new public service" in the government "is not at the helm, but service" point of view, that the service government is in the guidance of citizen and social standard, in the whole social democratic order framework, through legal procedures, set up according to citizen will the civil service for the purpose, to achieve service functions and social responsibility of the government.

In our country, the service-oriented government refers to a citizen in standard and social standard, the standard of rights under the guidance of the concept in the whole social democratic order framework, through legal procedures, set up according to the will of the citizens, aims to serve the people wholeheartedly, realize the service function and social responsibility of the government.

"Internet plus" drive, Shaanxi province municipal government and public affairs operations should be in line with WeChat to build a service-oriented government to strengthen the "Internet plus government service consciousness, optimize service processes, innovative services, promote data sharing, reduce the transaction costs of the system, the maximum profit of convenience, allowing users to run errands, less good things, no clogging, sharing the results of Internet plus government services development[3].

Habermas believes that under the "ideal communication context", if people can follow the basic requirements of statement, truthfulness, sincerity, standardization and correctness, mutual agreement can be reached, and effective communication can be achieved. Shaanxi province municipal government should strive to create "ideal communication situation", construct the backstage management system of effective communication.

"Internet plus" driven by the municipal government of Shaanxi Province, the WeChat public number should be specifically responsible for the operation of the office, the office of the administrative level directly accept the municipal government office leadership, accept the business publicity department and other relevant departments of the guidance, to ensure that the level of operations team can borrow to position the advantage and cross sectoral coordination, play the government departments and the general public media do not have the advantage. At the same time, the leaders of relevant departments should fully delegate the operation of the WeChat public operation team of the prefecture level municipal government. The daily information office will decide independently, implement the leadership of the relevant government departments and make decisions in a variety of ways, and establish an effective and flexible management mechanism across departments.

"Internet plus" driven by the municipal government of Shaanxi Province, WeChat public number by professional operations team, knowledge background and ability of team members should be able to achieve complementary requirements, team members work experience, full operational 
capacity, not only to master new media operation skills, and familiar with the work of the government and the needs of users, remain sensitive to policy, has the ability to show strong visual interpretation and policy, to work carefully, on the text, punctuation and other errors of zero tolerance[4].

"Internet plus" driven by the municipal government of Shaanxi Province, WeChat public operations on the project system as the core of the working mechanism, according to the different skills and background of team members and grasp the work of the team members, the task comes, managers can quickly set up a project team, the team members of the division of labor to complete the task; the operation team must adapt to the working mechanism of new media, 24 hours of work, set a fixed shift system, holidays should arrange staff on duty, to establish a scientific and effective working mechanism.

"Use and gratification" Mcguire's theory that the audience should use the media, get emotional conversion, and other information to meet. Shaanxi Province, the municipal government of WeChat public front operation should meet the needs of users, to provide a good experience for all users.

First, make clear the information release and functional location of the account.

"Internet plus" drive, Shaanxi province municipal government affairs public, WeChat should clear the account information and functionality, this part emphasizes the information types and authoritative and practical function in the real sense, is provided with the service function of "custom menu" in the page at the end of the micro construction of information service system publish, query and service as a whole.

"Internet plus" driven by the municipal government of Shaanxi Province, WeChat public number should determine the content innovation mechanism, innovation from the aspects of content and form, strengthen the push content, dedicated to the user to push the comprehensive, rich, close to the livelihood of their content, form a unique content push. At the same time, pay attention to the user to seek advice from more content and major public opinion response to the push push; pay attention to the content of human form to send presents, in the tone and wording, amiable and easy of approach and humorous, focused on WeChat language sense, easy interpretation and visual expression to text information, good use of multimedia communication, text pictures, audio, video and $\mathrm{H} 5$ flexible, strengthen user and platform stickiness through content innovation mechanism to push content and form two aspects[5].

"Internet plus" driven by the municipal government of Shaanxi Province, the WeChat public number to set up the user interaction mechanism of high efficiency, communication and service concept from a single information release mode change to the two-way interaction, take a variety of ways to interact with the user in the interactive content, messages and comments the timely processing of users, regularly create original interactive columns carry out a variety of activities, mobilize the enthusiasm of users to participate in interactive; in the interactive mode, through the automatic keyword matching and artificial reply two ways to carry out interactive with the user. To establish a timely and effective user interaction mechanism, to achieve effective communication with users, and to improve the user experience.

"Internet plus" drive, Shaanxi province municipal government affairs public, to create a new WeChat technology network integration mechanism, long-term "fragmentation, fight the enemy separately", scattered throughout the massive data effective integration, implementation of WeChat platform and the official website of the government and other related functions, data information services, collaborative sharing, establishment of the WeChat matrix, between the open Shaanxi municipal government in the public, WeChat and other functional departments channel, realize effective coordination between departments, public good service users[6].

\section{Acknowledgment}

Fund Project: This paper is an important phase achievement of The social science of Shaanxi province in 2016 of major theoretical and practical problems of project (project number: 2016C066) " The operating mechanism research of Shaanxi municipal government wechat public account was driven by 'Internet plus initiative" 


\section{References}

[1] Liang Xiaofeng, Li Xinhui. Function department government WeChat's way of survival [J]. news line, 2016 (01): 106-109.

[2] Zhu Ying, Ding Jie. Interaction between government WeChat and users from the perspective of interactive ritual chain [J]. news university, 2016, (04): 75-86.

[3]Zhang Yurong. Technical experts on government Tencent WeChat -- solve people "boduantui dilemma [J]. off, 2016, (06): 40-41.

[4] Yao Kaili. Research on the communication strategy of urban image issued by government WeChat [D]. Jinan University, 2016

[5] Yue. Government WeChat's functional positioning and communication strategy [D]. Jilin University, 2016.

[6] Li Tongjie. "Internet plus government": the innovation and development of [J]. Chinese management information, 2017, (07): 202-203. 